\title{
Foreword: special issue on innovation, communication and engineering
}

\author{
Bharat Bhushan ${ }^{1}$
}

Published online: 20 October 2021

(C) The Author(s), under exclusive licence to Springer-Verlag GmbH Germany, part of Springer Nature 2021

This special issue on Innovation, Communication and Engineering consists of selected papers presented at the International Conference on "Innovation, Communication and Engineering," in 2018.The conference covered broad topics, including information science, innovation design, industrial design, applied mathematics, computer science, cultural and creative research, electrical and electronic engineering, mechanical engineering, automation engineering, green technology and architectural engineering, material science, and other related fields.

Authors of selected papers from the conference were invited to submit full length papers for possible inclusion in this special issue of Microsystem Technologies (MST). The papers covered a wide range of fundamental studies, industrial practices, and engineering innovations by applying knowledge on microsystems. All papers were refereed according to the rigorous journal standards. The review process was coordinated by guest editors: Profs. Sheng-Joue Young and Ajit Khosla. Forty-five papers were accepted for publication in this issue.

We hope that readers find the papers in the issue to be informative.

Publisher's Note Springer Nature remains neutral with regard to jurisdictional claims in published maps and institutional affiliations.

Bharat Bhushan

bhushan100@outlook.com

1 The Ohio State University, San Jose, United States 